\title{
Activated Complex Approach to Describe Bovine Serum Albumin-Azure A and Bovine Serum Albumin-Azure B Intermolecular Interactions
}

\author{
Hauster M. C. de Paula, ${ }^{a}$ Yara L. Coelho, ${ }^{a}$ Alan S. B. de Castro, ${ }^{a}$ Jaqueline P. Rezende, ${ }^{b}$ \\ Ana C. S. Pires ${ }^{b}$ and Luis H. M. da Silva ${ }^{\circledR} *, a$ \\ ${ }^{a}$ Grupo de Química Verde Coloidal e Macromolecular (QUIVECOM), Departamento de Química, \\ Universidade Federal de Viçosa, Av. PH Rolfs, s/n, 36570-900 Viçosa-MG, Brazil \\ ${ }^{b}$ Grupo de Termodinâmica Molecular Aplicada (THERMA), Departamento de Tecnologia de Alimentos, \\ Universidade Federal de Viçosa, Av. PH Rolfs, s/n, 36570-900 Viçosa-MG, Brazil
}

\begin{abstract}
Azure A (AZA) and azure B (AZB) phenothiazine dyes are used for clinical and medical purposes, and their functions can be altered via interactions with proteins. However, no kinetics information on the interactions between phenothiazine dyes and bovine serum albumin (BSA) is available. Surface plasmon resonance was used to determine the energetic and dynamic of the BSA-AZA and BSA-AZB complexes formation at $\mathrm{pH} 7.4$. At temperature $\leq 16{ }^{\circ} \mathrm{C}$, the formation of activated $\left(\Delta \mathrm{H}_{\mathrm{a}, 12^{\circ} \mathrm{C}, \mathrm{AZA}}^{*}=-310.57 \mathrm{~kJ} \mathrm{~mol}^{-1}\right.$ and $\left.\Delta \mathrm{H}_{\mathrm{a}, 12}^{\ddagger}{ }^{\circ} \mathrm{C}, \mathrm{AZB}=-256.37 \mathrm{~kJ} \mathrm{~mol}^{-1}\right)$ and thermodynamically stable $\left(\Delta \mathrm{H}^{\circ}{ }_{12^{\circ} \mathrm{C}, \mathrm{AZA}}=-314.56 \mathrm{~kJ} \mathrm{~mol}^{-1}\right.$ and $\left.\Delta \mathrm{H}^{\circ}{ }_{12^{\circ} \mathrm{C}, \mathrm{AZB}}=-265.73 \mathrm{~kJ} \mathrm{~mol}^{-1}\right)$ complexes was driven by enthalpy, while at temperature $\geq 20^{\circ} \mathrm{C}$, by entropy, $\left(\mathrm{T} \Delta \mathrm{S}_{\mathrm{a}, 28^{\circ} \mathrm{C}, \mathrm{AZA}}^{\ddagger}=207.49\right.$ and $\mathrm{T} \Delta \mathrm{S}_{\mathrm{a}, 28^{\circ} \mathrm{C}, \mathrm{AZB}}^{\circ}=190.69 ; \mathrm{T} \Delta \mathrm{S}^{\circ}{ }_{28^{\circ} \mathrm{C}, \mathrm{AZA}}=277.50$ and $\left.\mathrm{T} \Delta \mathrm{S}^{\circ}{ }_{28^{\circ} \mathrm{C}, \mathrm{AZB}}=257.26 \mathrm{~kJ} \mathrm{~mol}^{-1}\right)$. Hydrophobic interactions were fundamental to the complex stability and the increase in number of $-\mathrm{CH}_{3}$ groups in the dyes do not affect kinetic and thermodynamic parameters. Our results could help optimize the medical and pharmaceutical applications of phenothiazine dyes.
\end{abstract}

Keywords: protein-dye interaction, BSA, phenothiazine dyes, thermodynamics, kinetics, SPR

\section{Introduction}

Several organic dye molecules have drawn attention recently owing to their different applications in the pharmaceutical, ${ }^{1}$ food, ${ }^{2}$ medical, ${ }^{3}$ and textile ${ }^{4}$ industries. In this context, the phenothiazine dyes, azure A and B (AZA and AZB, respectively), which feature similar molecular chemical structures (Figure 1), present broad applications in medicine owing to their high affinity for proteins..$^{5,6}$

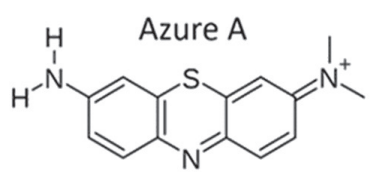<smiles>CNc1ccc2nc3ccc(=[N+](C)C)cc-3sc2c1</smiles>

Figure 1. Chemical structures of azure A and B dyes.

Azure A is used to diagnose amyloid accumulation, predict the extent of heart disease, as antimalarial, and as photo-chemotherapeutic agent against carcinomas., ${ }^{5,-9}$ Azure B also presents a variety of pharmacological properties,

*e-mail: luhen@ufv.br and is used to diagnose amyloid accumulation-related diseases, detect oral cancer, diagnose neurodegenerative diseases, and as inhibitor of $\beta$-amyloid protein filament. ${ }^{8,10,11}$ However, the functions and toxicity of AZA or AZB dyes can be altered by their interactions with proteins, such as bovine serum albumin (BSA), ${ }^{12}$ one of the most abundant protein in the bovine blood plasma.

$\mathrm{BSA}$ is responsible for maintaining the $\mathrm{pH}$ of the skin, helps control the colloidal osmotic pressure, and plays a dominant role in the disposal and transport of dyes, drugs, fatty acids, and endogenous and exogenous compounds in the bovine body. ${ }^{13}$ Despite the great importance of understanding BSA-AZA and BSA-AZB interactions, unfortunately only three papers ${ }^{5,14,15}$ have been published describing these types of bonding, in which, only one analyzed the thermodynamic interaction between these species $^{15}$ and none of them investigated the kinetics of the BSA-AZA or BSA-AZB complex formation.

The interactions of BSA with AZA or AZB were studied using spectroscopic techniques (ultraviolet-visible, Fouriertransform infrared, circular dichroism, and time-resolved fluorescence), ${ }^{5,14,15}$ and calorimetry. ${ }^{15}$ The results indicated 
that the AZA or AZB dyes were strongly bound to the hydrophobic Sudlow's site I of BSA and this process was enthalpy driven $\left(\Delta \mathrm{H}^{\circ}{ }_{\mathrm{AZA}}=-4.12 \pm 0.081 \mathrm{kcal} \mathrm{mol}^{-1}\right.$ and $\left.\Delta \mathrm{H}^{\circ}{ }_{\text {AZB }}=-2.38 \pm 0.041 \mathrm{kcal} \mathrm{mol}^{-1}\right) .{ }^{15}$ However, to the best of our knowledge, no kinetic studies on the interactions between BSA and AZA or AZB have been performed so far. Therefore, it is of great importance to describe the molecular dynamics of the BSA-AZA and BSA-AZB interactions, and to measure the thermodynamic parameters associated with these interactions using surface plasmon resonance (SPR). ${ }^{16}$

SPR is a free-labeled optical method for the realtime detection of interactions between proteins and different solutes, ${ }^{17-19}$ and its generated data would allow us to calculate the kinetic binding constants, such as the association rate constant $\left(\mathrm{k}_{\mathrm{a}}\right)$, dissociation rate constant $\left(\mathrm{k}_{\mathrm{d}}\right)$, as well as the thermodynamic binding constant $\left(\mathrm{K}_{\mathrm{b}}\right)$. From the temperature dependence of these kinetic and thermodynamic constants it would be possible to determine the following parameters: activation energy, changes in the Gibbs free energy, enthalpy, and entropy for the transition process, and changes in the standard Gibbs free energy, enthalpy, and entropy $\left(\mathrm{E}_{\mathrm{act}}^{\ddagger}, \Delta \mathrm{G}^{\ddagger}, \Delta \mathrm{H}^{\ddagger}, \Delta \mathrm{S}^{\ddagger}, \Delta \mathrm{G}^{\circ}, \Delta \mathrm{H}^{\circ}\right.$, and $\Delta S^{\circ}$, respectively). Recently, many researchers have reported the use of the SPR technology to investigate drug-protein, ${ }^{20-23}$ dye-protein, ${ }^{24,25}$ protein-food additive, ${ }^{18}$ protein-nanoparticle, ${ }^{26}$ low molecular substance-protein, ${ }^{27}$ polyphenol-protein ${ }^{28,29}$ interactions.

In this study, we investigated the interactions between BSA and AZA and AZB using the SPR technique and determined all kinetic and thermodynamic parameters for a better understanding of the molecular dynamics and energetic changes associated with these interactions.

\section{Experimental}

\section{Chemicals and apparatus}

Azure A (purity $\geq 70$ wt.\%), azure B (purity $\geq 89$ wt. $\%$ ), and BSA (purity $\geq 99$ wt.\%) were purchased from Sigma-Aldrich (Saint Louis, USA). All chemicals used in this study were of analytical grade and were used without further purification. Deionized water was used for all experiments.

Research-grade CM5 sensor chips and coupling reagents ( $N$-ethyl- $N{ }^{\prime}, N^{\prime}$ dimethylaminopropyl carbodiimide (EDC), $\mathrm{N}$-hydroxysuccinimide (NHS), and $1 \mathrm{M}$ ethanolamine hydrochloride, $\mathrm{pH}$ 8.5) were purchased from GE Healthcare (Pittsburgh, USA). All SPR experiments to investigate the kinetic and thermodynamic parameters of the BSA-AZA and BSA-AZB interactions were performed using a Biacore X100 instrument (GE Healthcare, Pittsburgh, USA).

\section{Solution preparation and method}

The CM5 chips were activated for 7 min using EDC/ NHS. Afterward, the excess activated carboxyl groups were blocked using ethanolamine for $7 \mathrm{~min}$. Subsequently, BSA was immobilized onto the chips $\left(15 \mu \mathrm{g} \mathrm{mL}^{-1}\right)$ in $10 \mathrm{mM}$ sodium acetate, $\mathrm{pH}$ 4.0. The immobilization of BSA was performed at low density (3728 resonance units (RUs)) to reduce any potential mass transport and crowding artifacts. During experiments using immobilized BSA, one flow cell was used as reference surface; this surface was prepared as describe above, but without BSA immobilization. ${ }^{30}$

Dye solutions were prepared at working concentrations (1-8 $\mu \mathrm{M})$ in flow buffer. Each dye concentration was injected under the surface of the chip with immobilized BSA (channel 1) for $15 \mathrm{~s}$ at the flow of $30 \mu \mathrm{L} \mathrm{min}^{-1}$ to allow binding. Then, the flow buffer was allowed to run through the surface to dissociate for $35 \mathrm{~s}$ at the flow of $30 \mu \mathrm{L} \mathrm{min}^{-1}$, to regenerate the surface of the chip. The procedure was performed for each AZA and AZB concentration. The channel without immobilized BSA (channel 2) underwent the same procedure. The RU response was obtained by subtracting the channel 2 response from the channel 1 . The BSA-dye binding experiments were performed at $\mathrm{pH} 7.4$ at temperatures ranging from 12 to $28^{\circ} \mathrm{C}$.

\section{Results and Discussion}

Analysis of BSA-AZA and BSA-AZB binding kinetics using SPR

The analysis of the SPR signal, i.e., RU dependence of time (RU $v s \mathrm{t}$ ), allowed us to obtain the $\mathrm{k}_{\mathrm{a}}$ and $\mathrm{k}_{\mathrm{d}}$ kinetic constants values of the intermolecular interactions between different compounds. In addition, the temperature dependence of $\mathrm{k}_{\mathrm{a}}$ and $\mathrm{k}_{\mathrm{d}}$ allowed us to analyze the energetic and molecular dynamics of the activated (transition) complex formation process. ${ }^{31}$ Figures $2 \mathrm{a}$ and $2 \mathrm{~b}$ illustrate the sensorgrams (RU vs. t) of the BSA-AZA and BSA-AZB interactions, respectively, in the concentration range of 1-8 $\mu \mathrm{M}$, using immobilized BSA at low density (3728 RU) on the surface of Biacore CM5 chips at $25{ }^{\circ} \mathrm{C}$. Similar results were obtained at other temperatures (Figures $\mathrm{S} 1$ and S2, Supplementary Information (SI) section).

The sensorgrams were obtained by subtracting the signal of the reference cell from the signals of the sample cells, and could be described using three regions (I, II, and III). In region I, called the baseline region, the buffer entered both the sample and reference cells, and therefore the difference between signals was close to zero. For region II $(0 \leq \mathrm{t} \leq 25 \mathrm{~s})$, the buffer-dye solutions entered 

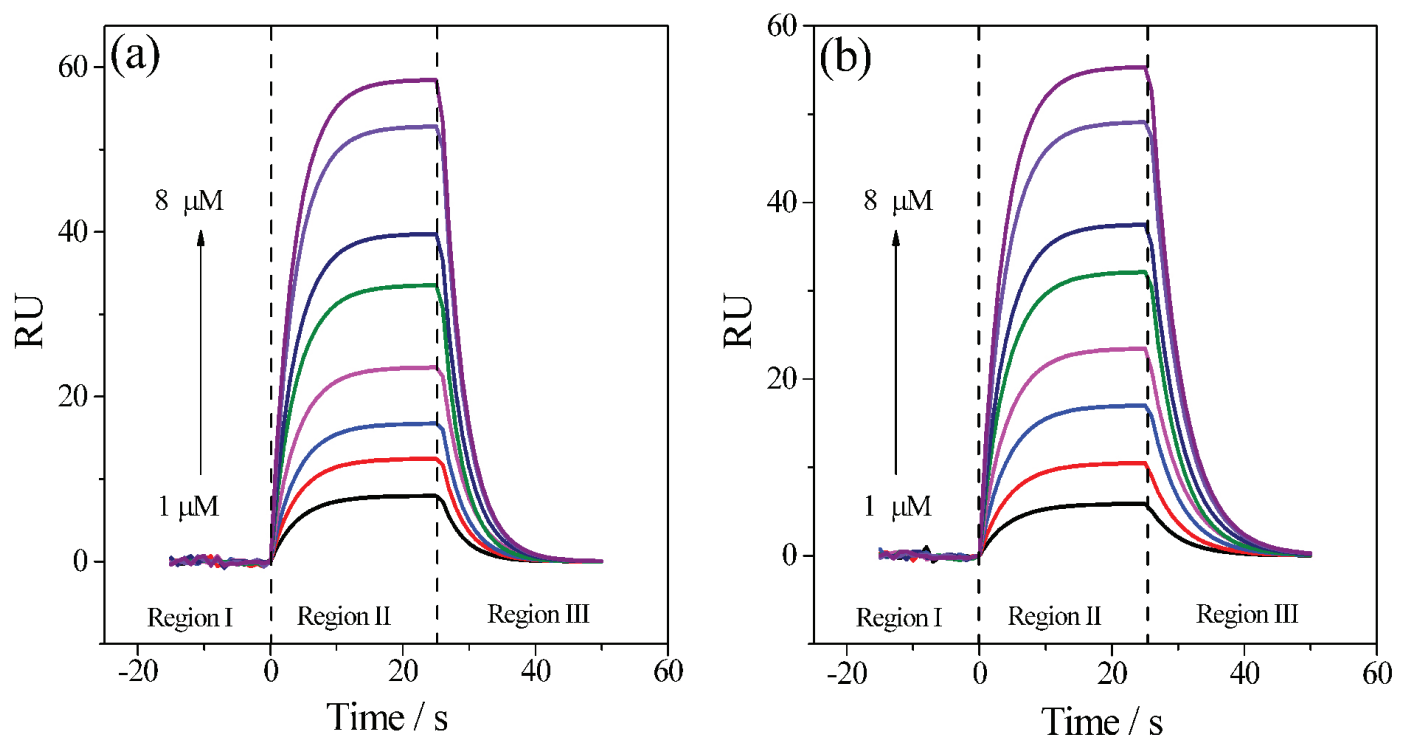

Figure 2. Sensorgrams of immobilized bovine serum albumin interactions with (a) azure A and (b) azure B at low density (3728 resonance units (RUs)) on surface of Biacore CM5 chips, at $25^{\circ} \mathrm{C} ; 1 \leq$ dye concentration $\leq 8 \mu \mathrm{M}$.

both cells causing the RU signal to grow continuously over time. During these $25 \mathrm{~s}$, associations between the free BSA and dye molecules and dissociations of the BSA-dye thermodynamic stable complexes adsorbed on the surfaces of the Biacore CM5 chips occurred simultaneously. After $25 \mathrm{~s}$, region III $(25<\mathrm{t} \leq 50 \mathrm{~s})$ started, and only pure buffer entered the reference and sample cells, again, which led to the decrease in the RU signals over time until the RU values became equal to the baseline signal. The decrease in the RU signals occurred because in region III the dissociation of the BSA-AZA and BSA-AZB complexes occurred predominantly.

The complex formation process attributed to the BSAAZA and BSA-AZB interactions could be described using a 1:1 reversible interaction model. The kinetics of the BSA-dye association and BSA-dye complex dissociation processes could be described using equation 1 .

$\mathrm{BSA}+$ dye $\underset{\mathrm{k}_{\mathrm{d}}}{\stackrel{\mathrm{k}_{\mathrm{a}}}{\rightleftharpoons}} \mathrm{BSA}-$ dye

where $\mathrm{k}_{\mathrm{a}}$ is the kinetic association constant of the free BSA and dye molecules for complex formation and $k_{d}$ is the kinetic dissociation constant of the BSA-dye complex. To elucidate the kinetics features of the process, calculating the $\mathrm{k}_{\mathrm{a}}$ and $\mathrm{k}_{\mathrm{d}}$ rate constants was required. ${ }^{32,33}$ Using global fitting analyses, all sensorgrams were fitted to equations 2 and 3 , which were, then, used to calculate the observed rate constant, $\mathrm{k}_{\mathrm{obs}}$, and $\mathrm{k}_{\mathrm{d}}$, respectively.

$\mathrm{RU}(\mathrm{t})=\mathrm{RU}_{\max }\left[1-\mathrm{e}^{-\mathrm{kobs}_{\text {ob }}(\mathrm{t})}\right]$

$R U(t)=R U\left(t_{f}\right) e^{-k_{d}\left(t-t_{f}\right)}$ where $R U(t)$ is the resonance response at time $t, R U_{\text {max }}$ is the maximum resonance response at $t=\infty$, and $R U\left(t_{f}\right)$ is the amplitude of the response at the end time of the buffer-dye flow. The $\mathrm{k}_{\mathrm{obs}}$ values were linearly dependent on the AZA and AZB concentrations (Figures S3a and S3b) for BSA-AZA and BSA-AZB, respectively), i.e., $\mathrm{k}_{\text {obs }}=\mathrm{k}_{\mathrm{a}}$ [dye] $+\mathrm{k}_{\mathrm{d}}$, where [dye] is the concentration of dye. This allowed us to calculate $\mathrm{k}_{\mathrm{a}}$ from the slope of the $\mathrm{k}_{\text {obs }} v s$. [dye] plot. Table 1 summarizes the kinetic parameters $\left(\mathrm{k}_{\mathrm{a}}\right.$ and $\mathrm{k}_{\mathrm{d}}$ ) values for the BSA-AZA and BSA-AZB complex formation processes at six different temperatures.

To the best of our knowledge, the kinetic constants of the BSA-AZA and BSA-AZB interactions have not been reported yet. The values of $k_{a}$ for the formation of the thermodynamically stable BSA-AZB complex and $\mathrm{k}_{\mathrm{d}}$ for the dissociation of that complex were higher than those for the BSA-AZA complex, which indicated that the increase in the number of $-\mathrm{CH}_{3}$ groups (AZA and AZB comprise 2 and $3-\mathrm{CH}_{3}$ groups, respectively) in the chemical structure of the dye sped up the formation and dissociation of complexes. The dissociation processes of both BSA-dye complexes were faster at higher temperature than at lower temperature. However, the temperature effect on the association process was different from that observed for the dissociation process. In the $12-20{ }^{\circ} \mathrm{C}$ temperature range, $\mathrm{k}_{\mathrm{a}}$ decreased as the temperature increased, while in the $20-28{ }^{\circ} \mathrm{C}$ temperature interval the opposite behavior was observed.

Sharma et al. ${ }^{5}$ and Sharma et al. ${ }^{14}$ reported that AZB and AZA bound to the same hydrophobic BSA site located in subdomain IIA of site I, and therefore, the differences in the kinetic parameters values for the formation and 
Table 1. Association $\left(\mathrm{k}_{\mathrm{a}}\right)$ and dissociation $\left(\mathrm{k}_{\mathrm{d}}\right)$ kinetic rate constants for bovine serum albumin-azure A (BSA-AZA) and bovine serum albumin-azure B (BSA-AZB) interactions at six different temperatures

\begin{tabular}{lccccc}
\hline \multirow{2}{*}{ Temperature $/{ }^{\circ} \mathrm{C}$} & \multicolumn{2}{c}{ BSA-AZA } & & \multicolumn{2}{c}{ BSA-AZB } \\
\cline { 2 - 3 } \cline { 5 - 6 } 12 & $\mathrm{k}_{\mathrm{a}} /\left(10^{3} \mathrm{M}^{-1} \mathrm{~s}^{-1}\right)$ & $\mathrm{k}_{\mathrm{d}} / \mathrm{s}^{-1}$ & & $\mathrm{k}_{\mathrm{a}} /\left(10^{3} \mathrm{M}^{-1} \mathrm{~s}^{-1}\right)$ & $0.250 \pm 0.008$ \\
16 & $9.40 \pm 0.31$ & $0.248 \pm 0.007$ & & $9.80 \pm 0.22$ & $0.268 \pm 0.019$ \\
20 & $2.80 \pm 0.15$ & $0.260 \pm 0.018$ & $3.60 \pm 0.21$ & $0.285 \pm 0.014$ \\
24 & $2.50 \pm 0.18$ & $0.274 \pm 0.017$ & $3.20 \pm 0.10$ & $0.305 \pm 0.015$ \\
25 & $4.60 \pm 0.24$ & $0.290 \pm 0.016$ & $5.40 \pm 0.36$ & $0.310 \pm 0.021$ \\
28 & $6.20 \pm 0.33$ & $0.295 \pm 0.018$ & & $7.40 \pm 0.49$ & $16.40 \pm 0.66$ \\
\hline
\end{tabular}

$\mathrm{k}_{\mathrm{a}}$ : kinetic association rate constant; $\mathrm{k}_{\mathrm{d}}$ : kinetic dissociation rate constant.

dissociation of the BSA-dye complexes were due to the dynamic structural change of the dyes, as well as, of the BSA interacting site. ${ }^{5,14}$

At $\mathrm{pH}$ 7.4, the dyes molecules were positively charged while BSA carried negative charge, which promoted favorable electrostatic interactions between BSA and the dyes. Despite the electrostatic repulsion between Congo red (CR) and BSA, as well as the large size of CR compared with those of AZA or AZB, the interaction between the free $\mathrm{CR}$ and $\mathrm{BSA}$ molecules occurred two to ten times faster than those between BSA-AZA and BSA-AZB. ${ }^{24}$ The higher rate for the CR-BSA complex formation was caused by the six free-rotating benzene rings present in the structure of CR, while AZA and AZB only comprise three condensed rings that were prevented from rotating to gain favorable conformations. Then, we could conclude that the CR molecules could self-orient faster than the AZA or AZB molecules, to form $\pi-\pi$ stacking interactions between the benzene rings and aromatic amino acids present at the BSA binding sites. However, these $\pi-\pi$ stacking interactions between CR and BSA caused the $k_{d}$ value for the BSA-CR complex formation to decrease six times compared with the values for the formation of the BSA-AZA and BSA-AZB complexes. To determine the energetic parameters associated with the BSA binding site conformation fit during the interaction with AZA and AZB, we investigated the temperature dependences of $k_{a}$ and $k_{d}$. The Arrhenius plots (Figures $3 \mathrm{a}$ and $3 \mathrm{~b}$ for BSA-AZA and BSA-AZB, respectively) are usually utilized to describe the temperature dependences of $k_{a}$ and $k_{d}$.

The temperature effect on the BSA-dye association processes was not linear, which suggested that the BSA-AZA and BSA-AZB interactions occurred via multi-step processes that were probably controlled by the site fitting on the BSA site I structure. However, the $\mathrm{k}_{\mathrm{d}}$ values for both thermodynamically stable complexes was
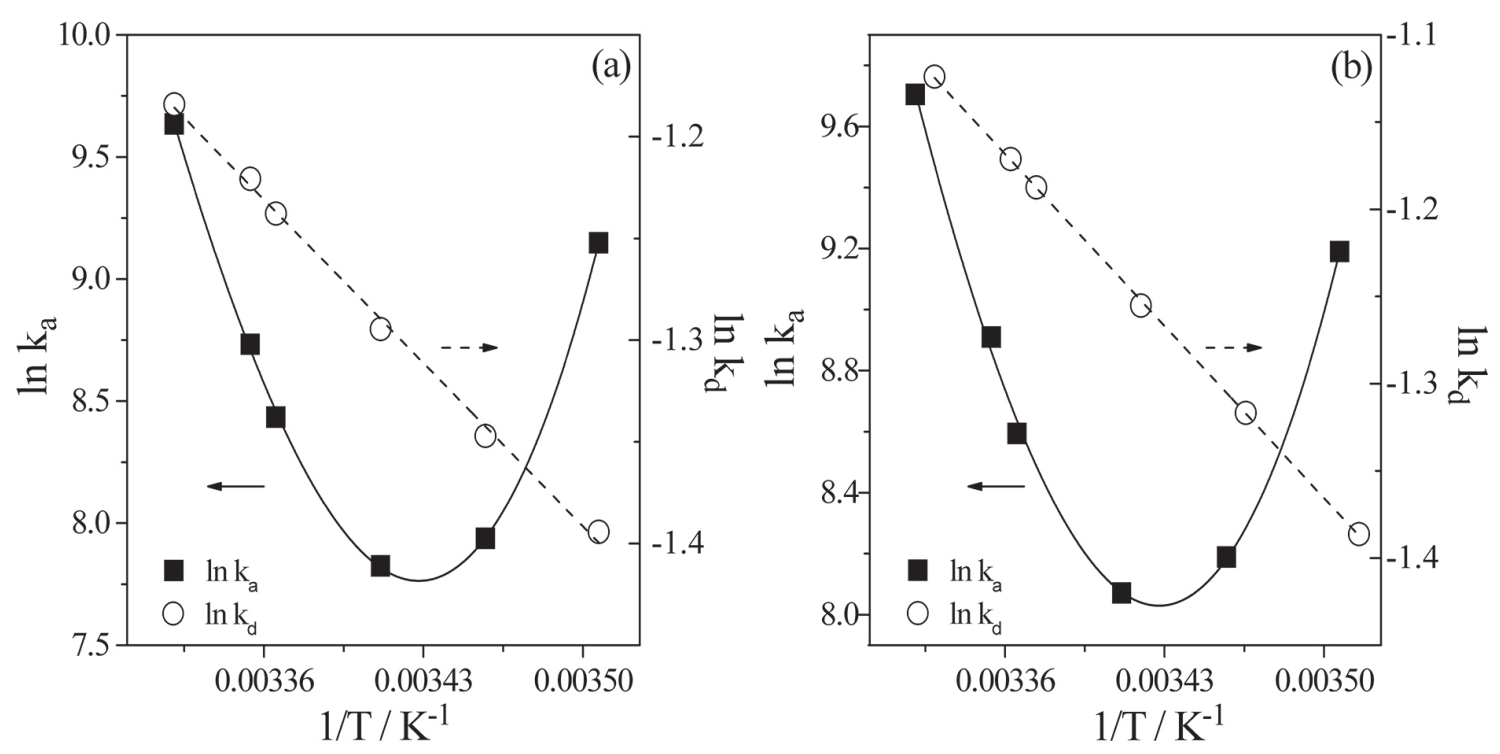

Figure 3. Arrhenius plots of $\ln \mathrm{k}_{\mathrm{a}}$ and $\ln \mathrm{k}_{\mathrm{d}}$ for (a) bovine serum albumin-azure A and (b) bovine serum albumin-azure B interactions as functions of reciprocal temperature. 
linearly dependent on temperature, which indicated that the dissociation processes occurred via single-step processes.

The energetic parameters related to the formation of the activated complexes from the associations of the free BSA and AZA and AZB molecules or from the dissociation of the BSA-AZA and BSA-AZB thermodynamically stable complexes, were obtained using the Arrhenius relationship $\left(\ln \mathrm{k}_{\mathrm{x}} v s .1 / \mathrm{T}\right)$.

$\mathrm{E}_{\mathrm{act}}=-\mathrm{R} \times\left(\frac{\mathrm{dln} \mathrm{k}_{\mathrm{x}}}{\mathrm{d}(1 / \mathrm{T})}\right)$

where $E_{\text {act }}$ is the activation energy $\left(\mathrm{J} \mathrm{mol}^{-1}\right), \mathrm{R}$ the universal gas constant $\left(8.314 \mathrm{~J} \mathrm{~mol}^{-1} \mathrm{~K}^{-1}\right)$, $\mathrm{T}$ is the temperature $(\mathrm{K})$, and $\mathrm{k}_{\mathrm{x}}=\mathrm{k}_{\mathrm{a}}$ or $\mathrm{k}_{\mathrm{d}}$.

To determine the activation complex energy parameters $\left(\Delta \mathrm{G}_{\mathrm{x}}^{\ddagger}, \Delta \mathrm{H}_{\mathrm{x}}^{\ddagger}\right.$, and $\left.\Delta \mathrm{S}_{\mathrm{x}}^{\ddagger}\right)$ involved in the formation of the transition complexes, we used equations 5-7.

$\Delta \mathrm{G}_{\mathrm{x}}^{\ddagger}=-\mathrm{RT} \ln \frac{\mathrm{k}_{\mathrm{x}} \mathrm{h}}{\mathrm{K}_{\mathrm{B}} \mathrm{T}}$
$\mathrm{E}_{\text {act }}=\Delta \mathrm{H}_{\mathrm{x}}^{\ddagger}+\mathrm{RT}$
$\mathrm{T} \Delta \mathrm{S}_{\mathrm{x}}^{\ddagger}=\Delta \mathrm{H}_{\mathrm{x}}^{\ddagger}-\Delta \mathrm{G}_{\mathrm{x}}^{\ddagger}$

where $\mathrm{k}_{\mathrm{x}}$ is the kinetic constant $\left(\mathrm{k}_{\mathrm{a}}\right.$ or $\left.\mathrm{k}_{\mathrm{d}}\right)$, $\mathrm{h}$ is Planck's constant $\left(6.6262 \times 10^{-34} \mathrm{~J} \mathrm{~s}\right)$, and $\mathrm{K}_{\mathrm{B}}$ is Boltzmann's constant $\left(1.38 \times 10^{-23} \mathrm{~J} \mathrm{~K}^{-1}\right)$. Table 2 summarizes the values of all parameters at six different temperatures.

The $E_{\text {act }}$ values for the formation of the activated complexes ([BSA-AZA $]^{\ddagger}$ and $\left.[\mathrm{BSA}-\mathrm{AZB}]^{\ddagger}\right)$ via the interactions of the free BSA and dyes molecules, were negative at lower temperatures and increased as the temperature increased, while $\mathrm{E}_{\text {act }}$ associated with the dissociation of the BSA-dye thermodynamic stable complexes was temperature independent.

Typically, $\mathrm{E}_{\text {act }}$ can be expressed as the sum of three energetic contributions, as follows: (i) desolvation energy, $\mathrm{E}_{\text {Des}}$, which is the energy required to remove the solvating layer of the free reagents; (ii) conformational change energy, $\mathrm{E}_{\text {conf }}$, which is associated with the biopolymer site fitting and dye chemical structure adjustment; and (iii) interaction energy, $\mathrm{E}_{\mathrm{int}}$, attributed to the interactions of the reactants (equation 8). Each one of these contributions could be temperature dependent.

$\mathrm{E}_{\mathrm{act}}=\mathrm{E}_{\mathrm{Des}}+\mathrm{E}_{\mathrm{inf}}+\mathrm{E}_{\mathrm{conf}}$

The $\mathrm{E}_{\text {Des }}$ term is positive, because to release the solvent from the solute solvation shell, energy should be absorbed from the surroundings to break up the solvent-solute interactions. Moreover, $\mathrm{E}_{\text {conf }}$ is positive, because it is associated with the breaking down of the amino acid-amino

Table 2. Thermodynamic parameters for (a) formation of transition BSA-AZA and BSA-AZB complexes and (d) dissociation of complexes in $12-28{ }^{\circ} \mathrm{C}$ temperature range

\begin{tabular}{|c|c|c|c|c|c|c|c|c|}
\hline \multirow{2}{*}{$\begin{array}{l}\text { Temperature / } \\
{ }^{\circ} \mathrm{C}\end{array}$} & \multicolumn{4}{|c|}{ Association phase (a) } & \multicolumn{4}{|c|}{ Dissociation phase (d) } \\
\hline & $\begin{array}{c}\mathrm{E}_{\text {act,a }} / \\
\left(\mathrm{kJ} \mathrm{mol}^{-1}\right) \\
\end{array}$ & $\begin{array}{c}\Delta \mathrm{H}_{\mathrm{a}}^{\ddagger} / \\
\left(\mathrm{kJ} \mathrm{mol}^{-1}\right)\end{array}$ & $\begin{array}{c}\Delta \mathrm{G}_{\mathrm{a}}^{\ddagger} / \\
\left(\mathrm{kJ} \mathrm{mol}^{-1}\right)\end{array}$ & $\begin{array}{c}\mathrm{T} \Delta \mathrm{S}_{\mathrm{a}}^{\ddagger} / \\
\left(\mathrm{kJ} \mathrm{mol}^{-1}\right) \\
\end{array}$ & $\begin{array}{c}\mathrm{E}_{\text {act,d }} / \\
\left(\mathrm{kJ} \mathrm{mol}^{-1}\right) \\
\end{array}$ & $\begin{array}{c}\Delta \mathrm{H}_{\mathrm{d}}^{\ddagger} / \\
\left(\mathrm{kJ} \mathrm{mol}^{-1}\right)\end{array}$ & $\begin{array}{c}\Delta \mathrm{G}_{\mathrm{d}}^{\ddagger} / \\
\left(\mathrm{kJ} \mathrm{mol}^{-1}\right)\end{array}$ & $\begin{array}{c}\mathrm{T} \Delta \mathrm{S}_{\mathrm{d}}^{\ddagger} / \\
\left(\mathrm{kJ} \mathrm{mol}^{-1}\right)\end{array}$ \\
\hline & \multicolumn{8}{|c|}{ BSA-AZA } \\
\hline 12 & $-308.20 \pm 46.30$ & $-310.57 \pm 46.60$ & $48.04 \pm 7.20$ & $-358.61 \pm 53.80$ & \multirow{6}{*}{$9.54 \pm 2.40$} & $7.17 \pm 1.10$ & $73.03 \pm 11.00$ & $-65.86 \pm 9.90$ \\
\hline 16 & $-102.63 \pm 48.30$ & $-105.03 \pm 49.50$ & $51.68 \pm 24.30$ & $-156.71 \pm 73.80$ & & $7.14 \pm 3.40$ & $74.00 \pm 34.80$ & $-66.86 \pm 31.50$ \\
\hline 20 & $52.53 \pm 16.20$ & $50.09 \pm 15.50$ & $52.68 \pm 16.30$ & $-2.59 \pm 0.80$ & & $7.11 \pm 2.20$ & $74.91 \pm 23.10$ & $-67.80 \pm 20.90$ \\
\hline 24 & $173.82 \pm 46.50$ & $171.35 \pm 45.90$ & $51.93 \pm 13.90$ & $119.42 \pm 32.00$ & & $7.07 \pm 1.90$ & $75.82 \pm 20.30$ & $-68.75 \pm 18.40$ \\
\hline 25 & $198.50 \pm 45.90$ & $196.02 \pm 45.30$ & $51.37 \pm 11.90$ & $144.65 \pm 33.40$ & & $7.07 \pm 1.60$ & $76.04 \pm 17.60$ & $-68.98 \pm 16.00$ \\
\hline \multirow[t]{2}{*}{28} & $259.64 \pm 59.30$ & $257.14 \pm 58.70$ & $49.65 \pm 11.30$ & $207.49 \pm 47.40$ & & $7.04 \pm 1.60$ & $76.74 \pm 17.50$ & $-69.70 \pm 15.90$ \\
\hline & \multicolumn{8}{|c|}{ BSA-AZB } \\
\hline 12 & $-254.00 \pm 29.10$ & $-256.37 \pm 29.40$ & $47.94 \pm 5.50$ & $-304.31 \pm 34.90$ & \multirow{6}{*}{$11.70 \pm 0.90$} & $9.34 \pm 1.10$ & $73.01 \pm 8.40$ & $-63.67 \pm 7.30$ \\
\hline 16 & $-87.27 \pm 18.30$ & $-89.67 \pm 18.80$ & $51.07 \pm 10.70$ & $-140.75 \pm 29.60$ & & $9.31 \pm 2.00$ & $73.93 \pm 15.50$ & $-64.62 \pm 13.60$ \\
\hline 20 & $44.82 \pm 12.00$ & $42.38 \pm 11.30$ & $52.08 \pm 13.90$ & $-9.70 \pm 2.60$ & & $9.28 \pm 2.50$ & $74.81 \pm 20.00$ & $-65.53 \pm 17.50$ \\
\hline 24 & $155.42 \pm 18.30$ & $152.95 \pm 18.00$ & $51.53 \pm 6.10$ & $101.42 \pm 11.90$ & & $9.24 \pm 1.10$ & $75.70 \pm 8.90$ & $-66.45 \pm 7.80$ \\
\hline 25 & $179.35 \pm 35.50$ & $176.88 \pm 35.10$ & $50.93 \pm 10.10$ & $125.94 \pm 25.00$ & & $9.24 \pm 1.80$ & $75.92 \pm 15.00$ & $-66.68 \pm 13.20$ \\
\hline 28 & $242.67 \pm 47.70$ & $240.17 \pm 47.20$ & $49.48 \pm 9.70$ & $190.69 \pm 37.50$ & & $9.21 \pm 1.80$ & $76.59 \pm 15.10$ & $-67.38 \pm 13.30$ \\
\hline
\end{tabular}

$\mathrm{E}_{\text {act.a: }}$ : activation energy for association phase; $\Delta \mathrm{H}_{\mathrm{a}}^{+}$: activation enthalpy change for association phase; $\Delta \mathrm{G}_{\mathrm{a}}^{\ddagger}$ : activation free energy change for association phase; $\Delta \mathrm{S}_{\mathrm{a}}^{\ddagger}$ : activation entropy change for association phase; $\mathrm{E}_{\text {act,d }}:$ activation energy for dissociation phase; $\Delta \mathrm{H}_{\mathrm{d}}^{\ddagger}$ : activation enthalpy change for dissociation phase; $\Delta \mathrm{G}_{\mathrm{d}}^{*}$ : activation free energy change for dissociation phase; $\Delta \mathrm{S}_{\mathrm{d}}^{\ddagger}$ : activation entropy change for dissociation phase; BSA-AZA: bovine serum albumin-azure A; BSA-AZB: bovine serum albumin-azure B. 
acid interactions that occur at BSA sites. However, $\mathrm{E}_{\text {int }}$ is negative, owing to the new intermolecular bonds formed by the BSA-dye interactions.

When the free BSA and dye molecules associated at $\mathrm{T}<20^{\circ} \mathrm{C}, \mathrm{E}_{\text {act,a }}$ was negative owing to two causes. (i) The magnitude of $\mathrm{E}_{\text {conf }}$ was low because at low temperature the molecular kinetic average energy was not high enough, and therefore, the energy transfer from particle collisions was not sufficient to overcome the potential energy barrier associated with the BSA site conformational change. This conferred a less flexible character to this interacting site. (ii) Consequently, the dye molecules could not penetrate much inside the BSA molecules sites, which promoted the release of small amounts of water molecules from the solvation shells of BSA and dyes, and therefore, caused the small $E_{\text {Des }}$ values. Subsequently, $\left|E_{\text {Des }}+E_{\text {conf }}\right|<\left|E_{\text {int }}\right|$.

As the temperature increased (and consequently the molecular average kinetic energy increased), the energy transferred via molecular collisions increased, which caused intense conformational changes to the BSA interacting sites, and therefore induced higher degrees of dye penetration, as well as, the intense desolvation of interacting molecules. This intensification of the conformational site changes and the desolvation process promoted by the increase in temperature caused $\mathrm{E}_{\text {act,a }}$ to became positive, and therefore, $\left|E_{\text {Des }}+E_{\text {conf }}\right|>\left|E_{\text {int }}\right|$. The same analysis could be applied to $\Delta \mathrm{H}_{\mathrm{a}}^{\ddagger}$ and $\mathrm{T} \Delta \mathrm{S}_{\mathrm{a}}^{\ddagger}$.

During the association process of the free BSA and dyes molecules in the $12-20{ }^{\circ} \mathrm{C}$ temperature range, $\Delta \mathrm{G}_{\mathrm{a}}^{\ddagger}$ increased as the temperature increased, while the opposite behavior was observed in the $20-28^{\circ} \mathrm{C}$ temperature range. In addition, $\Delta \mathrm{G}_{\mathrm{a}}^{\ddagger}$ remained fairly constant (approximately $50 \mathrm{~kJ} \mathrm{~mol}^{-1}$ ), and $\Delta \mathrm{H}_{\mathrm{a}}^{\ddagger}$ and $\mathrm{T} \Delta \mathrm{S}_{\mathrm{a}}^{\ddagger}$ changed much more than $\Delta \mathrm{G}_{\mathrm{a}}^{\ddagger}$, which suggested the possible activation enthalpyentropy compensation. To verify the occurrence of this compensation process we have plotted $\Delta \mathrm{H}_{\mathrm{a}}^{\ddagger}$ as function of $\mathrm{T} \Delta \mathrm{S}_{\mathrm{a}}^{\ddagger}$ for the formation of the $[\mathrm{BSA}-\mathrm{AZA}]^{\ddagger}$ and [BSA-AZB] transition complexes (Figure 4).

The relationships between $\Delta \mathrm{H}_{\mathrm{a}}^{\ddagger}$ and $\mathrm{T} \Delta \mathrm{S}_{\mathrm{a}}^{\ddagger}$ were linear, and the correlation coefficients, $\mathrm{r}^{2}$, were equal to 0.999 for the BSA-dye association processes, which demonstrated that the BSA-AZA and BSA-AZB interactions occurred via an iso-kinetic enthalpy-entropy compensation process. The linear relationship between $\Delta \mathrm{H}_{\mathrm{a}}^{\ddagger}$ and $\mathrm{T} \Delta \mathrm{S}_{\mathrm{a}}^{\ddagger}$ could be expressed using equation 9 .

$\Delta \mathrm{H}_{\mathrm{a}}^{\ddagger}=\alpha-\beta \mathrm{T} \Delta \mathrm{S}_{\mathrm{a}}^{\ddagger}$

where $\alpha$ and $\beta$ are adjustable constants. Here, $\alpha$ ca. $54 \mathrm{~kJ} \mathrm{~mol}^{-1}$ and $\beta$ ca. $291 \mathrm{~K}$ are $\Delta \mathrm{G}_{\mathrm{a}}^{\ddagger}$ and the compensation temperature, respectively. This iso-kinetic compensation revealed the

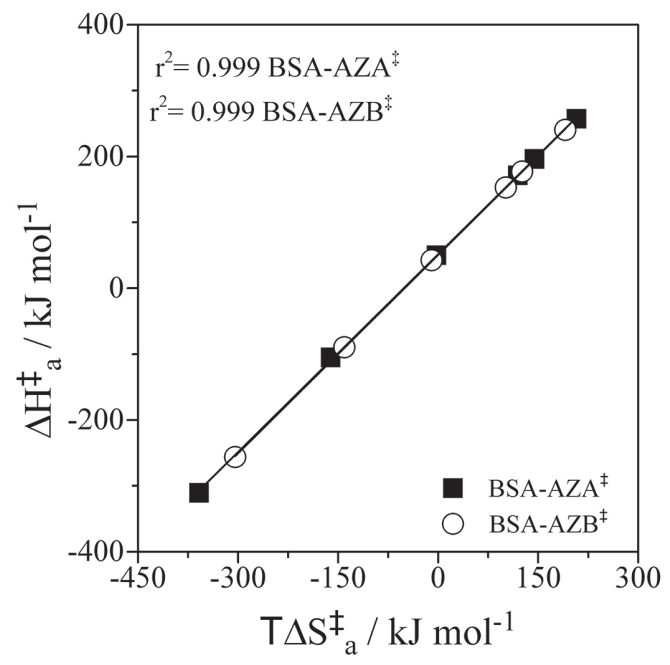

Figure 4. Enthalpy-entropy $\left(\Delta \mathrm{H}_{\mathrm{a}}^{\ddagger}-\mathrm{T} \Delta \mathrm{S}_{\mathrm{a}}^{\ddagger}\right)$ plots for [BSA-AZA $]^{\ddagger}$ and [BSA-AZB] transition complexes (here, BSA, AZA, and AZB are bovine serum albumin, azure $\mathrm{A}$, and azure $\mathrm{B}$, respectively).

typical activated energetic signature for the hydrophobic interactions, which was promoted by the changes in the structure of the solvation layers of the interacting molecules, i.e., during the association process of the free BSA and dyes molecules, two sub-process could occur: (i) BSA and dye desolvation and (ii) direct interactions between the desolvated BSA and dyes molecules. The $\Delta \mathrm{H}_{\mathrm{a}}^{\ddagger}$ and $\mathrm{T} \Delta \mathrm{S}_{\mathrm{a}}^{\ddagger}$ values associated with the first and second sub-processes were positive and negative, respectively. During the BSA-dye association process at $\mathrm{T}<20^{\circ} \mathrm{C}$, the desolvated BSA-dye direct interaction dominated the magnitudes of $\Delta \mathrm{H}_{\mathrm{a}}^{\ddagger}$ and $\mathrm{T} \Delta \mathrm{S}_{\mathrm{a}}^{\ddagger}$, mainly because in this temperature range, the desolvation process occurred at low extent. However, as the temperature increased, the release of water molecule solvating the free BSA and dyes molecules determined the $\Delta \mathrm{H}_{\mathrm{a}}^{\ddagger}$ and $\mathrm{T} \Delta \mathrm{S}_{\mathrm{a}}^{\ddagger}$ values, and caused both activated kinetic parameters to be positive at higher temperatures. ${ }^{34,35}$

The transformation processes of the $[\mathrm{BSA}-\mathrm{AZA}]^{\ddagger}$ and [BSA-AZB] transition complexes into the final BSA-AZA and BSA-AZB thermodynamically stable complexes, respectively, were accompanied by corresponding enthalpy releases of 7.07 and $9.24 \mathrm{~kJ} \mathrm{~mol}^{-1}$. However, these processes caused large entropy increases for BSA-AZA and BSA-AZB ( 69 and $67 \mathrm{~kJ} \mathrm{~mol}^{-1}$, respectively), and therefore the transformation of the [BSA-dyes] $]^{\ddagger}$ transition complexes into thermodynamically stable BSA-dye complexes was driven by biopolymer and dyes conformational changes.

Analysis of thermodynamic parameters of BSA-AZA and BSA-AZB binding

To determine the stability and driving force for the formation of the thermodynamically stable BSA-dye 
complexes, it was necessary to measure the following standard thermodynamic parameters for the complex formation: $\Delta \mathrm{G}^{\circ}, \Delta \mathrm{H}^{\circ}$, and $\left(\Delta \mathrm{S}^{\circ}\right)$. All these thermodynamic parameters represented the changes in the thermodynamic properties of the system when 1 mol complex was formed after 1 mol BSA and 1 mol dye interacted. By considering that the BSA-dye complexes were formed via unimolecular mechanisms, $K_{b}$ could be calculated using the classic relationship, $\mathrm{K}_{\mathrm{b}}=\mathrm{k}_{\mathrm{a}} / \mathrm{k}_{\mathrm{d}} \cdot{ }^{20}$ From the $\mathrm{K}_{\mathrm{b}}$ values (equation 10) and its temperature dependence (equation 11) (Figure S4, SI section), we could calculate $\Delta \mathrm{G}^{\circ}$ and $\Delta \mathrm{H}^{\circ}$, while $\mathrm{T} \Delta \mathrm{S}^{\circ}$ could be determined using the fundamental thermodynamic equation (equation 12).

$\Delta \mathrm{G}^{\circ}=-\mathrm{RT} \ln \mathrm{K}_{\mathrm{b}}$

$\ln \frac{\mathrm{K}_{\mathrm{b} 2}}{\mathrm{~K}_{\mathrm{b} 1}}=-\frac{\Delta \mathrm{H}^{\circ}}{\mathrm{R}}\left(\frac{1}{\mathrm{~T}_{2}}-\frac{1}{\mathrm{~T}_{1}}\right)$

$\mathrm{T} \Delta \mathrm{S}^{\circ}=\Delta \mathrm{H}^{\circ}-\Delta \mathrm{G}^{\circ}$

Table 3 lists the values of the thermodynamic parameters for the formation of the BSA-AZA and BSAAZB complexes at different temperatures.

All thermodynamic parameters values were temperature dependent and followed second order polynomial trends as the temperature increased. As the temperature increased, $\Delta \mathrm{G}^{\circ}$ increased until it reached the maximum value at $\mathrm{T}=20^{\circ} \mathrm{C}$, and then decreased as the temperature continued to increase. Both $\Delta \mathrm{H}^{\circ}$ and $\mathrm{T} \Delta \mathrm{S}^{\circ}$ increased monotonically as the temperature increased. The $\Delta \mathrm{G}^{\circ}$ values were negative at all temperatures, which demonstrated that for the mixtures of BSA and AZA or AZB aqueous solutions, the thermodynamic equilibrium conditions promoted higher concentrations of the BSA-AZA and BSA-AZB complexes. The chemical structure differences between dyes did not affect the magnitude of $\Delta \mathrm{G}^{\circ}$. Sharma et al. ${ }^{5}$ and
Sharma et al. ${ }^{14}$ used fluorescence spectroscopy to determine the $\Delta \mathrm{G}^{\circ}$ values for the BSA-AZA and BSA-AZB complexes ( -30.35 and $-33.61 \mathrm{~kJ} \mathrm{~mol}^{-1}$, respectively) which differed by approximately $20 \%$ from our results. Unfortunately, the authors did not calculate the $\Delta \mathrm{H}^{\circ}$ or $\mathrm{T} \Delta \mathrm{S}^{\circ}$ parameters for these complexes. The small differences between the results reported by Sharma et al. ${ }^{5}$ and Sharma et al. ${ }^{14}$ and $\Delta \mathrm{G}^{\circ}$ values obtained in this study could be attributed to the smaller configuration entropy contribution during the SPR experiment, which was mainly due to the protein molecules attached to the surfaces of these chips. To investigate the driving force of the BSA-dye complexes formation, we needed to analyze the thermodynamic potential components $\Delta \mathrm{H}^{\circ}$ and $\mathrm{T} \Delta \mathrm{S}^{\circ}$. Both thermodynamic parameters were negative at low temperatures and became positive at $\mathrm{T}=20^{\circ} \mathrm{C}$. Both the BSA-AZA and BSA-AZB interactions occurred via enthalpy-entropy compensation (Figure S5, SI section), which demonstrated that, as observed for the activated complex formation, during the synthesis of the thermodynamically stable complexes it was the hydrophobic interaction (release of water from the solvation shells of the BSA and dyes molecules and direct desolvated BSA and dye interactions) that determined the molecular mechanism for the formation of the BSA-dye complexes. This temperature increase effect on the BSA-AZA and BSA-AZB hydrophobic interaction could be associated with the partial destruction of the folded protein structure, exposing the inner hydrophobic core.

\section{Conclusions}

The SPR technique confirmed that BSA interacted with phenothiazine dyes (AZA and AZB) to forming thermodynamically stable complexes $\left(\mathrm{K}_{\mathrm{b}}\right.$ of $2.1 \times 10^{4}$ and $2.39 \times 10^{4} \mathrm{M}^{-1}$, respectively, at $25^{\circ} \mathrm{C}$ ) at $\mathrm{pH}$ 7.4. However, the driving force for the formation of the BSA-phenothiazine

Table 3. Standard Gibbs free energy, enthalpy, and entropic parameter changes $\left(\Delta \mathrm{G}^{\circ}, \Delta \mathrm{H}^{\circ}\right.$, and $\left.\mathrm{T} \Delta \mathrm{S}^{\circ}\right)$ for formation of BSA-AZA and BSA-AZB complexes at temperatures in the $12-28^{\circ} \mathrm{C}$ range and $\mathrm{pH} 7.4$

\begin{tabular}{|c|c|c|c|c|c|c|c|c|}
\hline \multirow{2}{*}{$\begin{array}{l}\text { Temperature / } \\
{ }^{\circ} \mathrm{C}\end{array}$} & \multicolumn{4}{|c|}{ BSA-AZA } & \multicolumn{4}{|c|}{ BSA-AZB } \\
\hline & $\begin{array}{c}\mathrm{K}_{\mathrm{b}} / \\
\left(10^{4} \mathrm{~L} \mathrm{~mol}^{-1}\right)\end{array}$ & $\begin{array}{c}\Delta \mathrm{H}^{\circ} / \\
\left(\mathrm{kJ} \mathrm{mol}^{-1}\right)\end{array}$ & $\begin{array}{c}\Delta \mathrm{G}^{\circ} / \\
\left(\mathrm{kJ} \mathrm{mol}^{-1}\right)\end{array}$ & $\begin{array}{c}\mathrm{T} \Delta \mathrm{S}^{\circ} / \\
\left(\mathrm{kJ} \mathrm{mol}^{-1}\right)\end{array}$ & $\begin{array}{c}\mathrm{K}_{\mathrm{b}} / \\
\left(10^{4} \mathrm{~L} \mathrm{~mol}^{-1}\right)\end{array}$ & $\begin{array}{c}\Delta \mathrm{H}^{\circ} / \\
\left(\mathrm{kJ} \mathrm{mol}^{-1}\right) \\
\end{array}$ & $\begin{array}{c}\Delta \mathrm{G}^{\circ} / \\
\left(\mathrm{kJ} \mathrm{mol}^{-1}\right)\end{array}$ & $\begin{array}{c}\mathrm{T} \Delta \mathrm{S}^{\circ} / \\
\left(\mathrm{kJ} \mathrm{mol}^{-1}\right)\end{array}$ \\
\hline 12 & $3.79 \pm 0.60$ & $-314.56 \pm 47.20$ & $-24.99 \pm 3.80$ & $-289.57 \pm 43.50$ & $3.92 \pm 0.40$ & $-265.73 \pm 30.50$ & $-25.07 \pm 2.90$ & $-240.6 \pm 27.60$ \\
\hline 16 & $1.08 \pm 0.50$ & $-111.69 \pm 52.60$ & $-22.33 \pm 10.50$ & $-89.37 \pm 42.10$ & $1.34 \pm 0.30$ & $-99.29 \pm 20.80$ & $-22.86 \pm 4.80$ & $-76.43 \pm 16.00$ \\
\hline 20 & $0.91 \pm 0.30$ & $42.22 \pm 13.00$ & $-22.22 \pm 6.90$ & $64.44 \pm 19.90$ & $1.12 \pm 0.30$ & $32.58 \pm 8.70$ & $-22.73 \pm 6.10$ & $55.31 \pm 14.80$ \\
\hline 24 & $1.59 \pm 0.40$ & $163.47 \pm 43.80$ & $-23.89 \pm 6.40$ & $187.36 \pm 50.10$ & $1.77 \pm 0.20$ & $143.01 \pm 16.80$ & $-24.17 \pm 2.80$ & $167.18 \pm 19.70$ \\
\hline 25 & $2.10 \pm 0.50$ & $188.32 \pm 43.50$ & $-24.67 \pm 5.70$ & $212.99 \pm 49.30$ & $2.39 \pm 0.50$ & $166.91 \pm 33.10$ & $-24.99 \pm 5.00$ & $191.90 \pm 38.00$ \\
\hline 28 & $5.00 \pm 1.10$ & $250.41 \pm 57.20$ & $-27.09 \pm 6.20$ & $277.50 \pm 63.40$ & $5.05 \pm 1.00$ & $230.14 \pm 45.30$ & $-27.11 \pm 5.30$ & $257.26 \pm 50.60$ \\
\hline
\end{tabular}

$\mathrm{K}_{\mathrm{b}}$ : binding constant; $\Delta \mathrm{G}^{\circ}$ : standard Gibbs free energy change; $\Delta \mathrm{H}^{\circ}$ : standard enthalpy change; $\Delta \mathrm{S}^{\circ}$ : standard entropy change; BSA-AZA: bovine serum albumin-azure A; BSA-AZB: bovine serum albumin-azure. 
dye complexes was temperature dependent. At temperature $\leq 16{ }^{\circ} \mathrm{C}$, enthalpic forces, mainly owing to hydrogen bonding and van der Waals interactions, governed the formation of complexes $\left(\Delta \mathrm{H}^{\circ}{ }_{12^{\circ} \mathrm{C}, \mathrm{AZA}}=-314.56 \mathrm{~kJ} \mathrm{~mol}^{-1}\right.$ and $\left.\Delta \mathrm{H}^{\circ}{ }_{12}^{\circ} \mathrm{C}, \mathrm{AZB}=-265.73 \mathrm{~kJ} \mathrm{~mol}^{-1}\right)$, while at temperature $\geq 20{ }^{\circ} \mathrm{C}$, owing to the predominance of the hydrophobic interactions, the driving force was the entropy $\left(\mathrm{T} \Delta \mathrm{S}^{\circ}{ }_{28^{\circ} \mathrm{C}, \mathrm{AZA}}=277.50 \mathrm{~kJ} \mathrm{~mol}^{-1}\right.$ and $\left.\mathrm{T} \Delta \mathrm{S}^{\circ}{ }_{28^{\circ} \mathrm{C}, \mathrm{AZB}}=257.26 \mathrm{~kJ} \mathrm{~mol}^{-1}\right)$. The results of this study suggested that BSA interacted with AZA and AZB via transition complexes. Proteindye associations occurred via multi-step processes and the activation energy values increases as the temperature increased $\left(\mathrm{E}_{\mathrm{act}, \mathrm{a}, 12^{\circ} \mathrm{C}, \mathrm{AZA}}=-308.20 \mathrm{~kJ} \mathrm{~mol}^{-1}\right.$ increased to $\mathrm{E}_{\mathrm{act}, \mathrm{a}, 28^{\circ} \mathrm{C}, \mathrm{AZA}}=259.64 \mathrm{~kJ} \mathrm{~mol}^{-1}$, and $\mathrm{E}_{\mathrm{act}, \mathrm{a}, 12^{\circ} \mathrm{C}, \mathrm{AZB}}=-254.00 \mathrm{~kJ} \mathrm{~mol}^{-1}$ increased to $\mathrm{E}_{\mathrm{act}, \mathrm{a}, 28^{\circ} \mathrm{C}, \mathrm{AZB}}=242.67 \mathrm{~kJ} \mathrm{~mol}^{-1}$ ). On the other hand, during the dissociation of the thermodynamically stable BSA-AZA and BSA-AZB complexes into activated complexes, singlestep processes occurred $\left(\mathrm{E}_{\text {act,d,AZA }}=9.54 \pm \mathrm{kJ} \mathrm{mol}^{-1}\right.$ and $\mathrm{E}_{\mathrm{act}, \mathrm{d}, \mathrm{AZB}}=11.70 \mathrm{~kJ} \mathrm{~mol}^{-1}$ ). The thermodynamically stable BSA-AZA and BSA-AZB complexes formed via enthalpyentropy compensation processes, and the [BSA-AZA] and $[\mathrm{BSA}-\mathrm{AZB}]^{*}$ activated complexes were produced via iso-kinetic compensation. The kinetic and thermodynamic analyses of the interactions between the AZA and AZB dyes and BSA could help elucidate the molecular mechanism of complex formation between organic dyes and different proteins, which could prove useful for designing proteinbinding therapeutic molecules.

\section{Supplementary Information}

Supplementary information is available free of charge at http://jbcs.sbq.org.br as PDF file.

\section{Acknowledgments}

This work was supported by the Coordenação de Aperfeiçoamento de Pessoal de Nível Superior (CAPES), Conselho Nacional de Desenvolvimento Científico e Tecnológico (CNPq), and Fundação de Apoio à Pesquisa de Minas Gerais (FAPEMIG).

\section{Author Contributions}

Hauster Maximiler Campos de Paula was responsible for the conceptualization, data curation, formal analysis, investigation, methodology, visualization, writing original draft, review and editing; Yara Luiza Coelho for the data curation, investigation, methodology, visualization, writing original draft, review and editing; Alan Stampini Benhame de Castro for the data curation, formal analysis, methodology and visualization; Jaqueline de Paula Rezende for the data curation, investigation, methodology, writing review and editing; Ana Clarissa dos Santos Pires for the conceptualization, funding acquisition, resources, supervision; visualization, writing original draft, review and editing; Luis Henrique Mendes da Silva for the conceptualization, funding acquisition, investigation, methodology, project administration, resources, supervision; visualization, writing original draft, review and editing.

\section{References}

1. Rajan, D.; Ilanchelian, M.; Int. J. Biol. Macromol. 2018, 113, 1052.

2. Dotto, G. L.; Pinto, L. A. A.; Hachicha, M. A.; Knani, S.; Food Chem. 2015, 171, 1 .

3. Blivis, D.; Falgairolle, M.; O’Donovan, M. J.; Sci. Rep. 2019, 9, 3201 .

4. Soares, O. S. G. P.; Órfão, J. J. M.; Portela, D.; Vieira, A.; Pereira, M. F. R.; J. Hazard. Mater. 2006, 137, 1664.

5. Sharma, A. S.; Anandakumar, S.; Ilanchelian, M.; RSC Adv. 2014, 4, 36267.

6. Moreira, L. M.; Lyon, J. P.; Romani, A. P.; Severino, D.; Rodrigues, M. R.; de Oliveira, H. P. M. In Advanced Aspects of Spectroscopy; Farrukh, M. A., ed.; InTech: Rijeka, Croatia, 2012, p. 393-422.

7. Vennerstrom, J. L.; Makler, M. T.; Angerhofer, C. K.; Williams, J. A.; Antimicrob. Agents Chemother. 1995, 39, 2671.

8. Khan, A. Y.; Suresh Kumar, G.; J. Chem. Thermodyn. 2015, 91, 225.

9. Diabou Gaye-Seye, M.; Aaron, J.-J.; Parkanyi, C.; Motohashi, N.; Curr. Drug Targets 2006, 7, 1083.

10. Oz, M.; Lorke, D. E.; Petroianu, G. A.; Biochem. Pharmacol. 2009, 78, 927.

11. Delport, A.; Harvey, B. H.; Petzer, A.; Petzer, J. P.; Life Sci. 2014, 117, 56.

12. Flarakos, J.; Morand, K. L.; Vouros, P.; Anal. Chem. 2005, 77, 1345.

13. Mathew, T. V.; Kuriakose, S.; Colloids Surf., B 2013, 101, 14.

14. Sharma, A. S.; Subramanian, N.; Malaichamy, I.; J. Photochem. Photobiol., B 2016, 164, 212.

15. Das, S.; Islam, M. M.; Jana, G. C.; Patra, A.; Jha, P. K.; Hossain, M.; J. Mol. Recognit. 2017, 30, e2609.

16. Amaral, M.; Kokh, D. B.; Bomke, J.; Wegener, A.; Buchstaller, H. P.; Eggenweiler, H. M.; Matias, P.; Sirrenberg, C.; Wade, R. C.; Frech, M.; Nat. Commun. 2017, 8, 2276.

17. Hudson, E. A.; de Paula, H. M. C.; da Silva, R. M.; Pires, A. C. S.; da Silva, L. H. M.; Int. J. Biol. Macromol. 2019, 133, 860. 
18. Fathi, F.; Mohammadzadeh-Aghdash, H.; Sohrabi, Y.; Dehghan, P.; Dolatabadi, J. E. N.; Food Chem. 2018, 246, 228.

19. Taghipour, P.; Zakariazadeh, M.; Sharifi, M.; Dolatabadi, J. E. N.; Barzegar, A.; J. Photochem. Photobiol., B 2018, 183, 11.

20. Juhász, Á.; Luty-Błocho, M.; Wojnicki, M.; Tóth, G. K.; Csapó, E.; Microchem. J. 2019, 147, 311.

21. Lima, C. H. M.; de Paula, H. M. C.; da Silva, L. H. M.; Rocha, M. S.; Biopolymers 2017, 107, e23071.

22. Mowla, R.; Wang, Y.; Ma, S.; Venter, H.; Biochim. Biophys. Acta, Biomembr. 2018, 1860, 878.

23. Patching, S. G.; Biochim. Biophys. Acta, Biomembr. 2014, 1838, 43.

24. de Paula, H. M. C.; Coelho, Y. L.; Agudelo, A. J. P.; Rezende, J. P.; Ferreira, G. M. D.; Ferreira, G. M. D.; Pires, A. C. S.; da Silva, L. H. M.; Colloids Surf., B 2017, 159, 737.

25. Coelho, Y. L.; de Paula, H. M. C.; Agudelo, A. J. P.; de Castro, A. S. B.; Hudson, E. A.; Pires, A. C. S.; da Silva, L. H. M.; Int. J. Biol. Macromol. 2019, 136, 559.

26. Atale, S. S.; Dyawanapelly, S.; Jagtap, D. D.; Jain, R.; Dandekar, P.; Int. J. Biol. Macromol. 2019, 123, 97.

27. Patil, S.; Sistla, S.; Jadhav, J.; Int. J. Biol. Macromol. 2016, 92 , 1123.
28. Rezende, J. P.; Hudson, E. A.; de Paula, H. M. C.; Coelho, Y. L.; da Silva, L. H. M.; Pires, A. C. S.; Food Hydrocolloids 2019, 95, 526.

29. Rezende, J. P.; Hudson, E. A.; de Paula, H. M. C.; Meinel, R. S.; da Silva, A. D.; Pires, A. C. S.; da Silva, L. H. M.; Food Chem. 2020, 307, 125514.

30. Drake, A. W.; Tang, M. L.; Papalia, G. A.; Landes, G.; HaakFrendscho, M.; Klakamp, S. L.; Anal. Biochem. 2012, 429, 58.

31. Schubert, F.; Zettl, H.; Häfner, W.; Krauss, G.; Krausch, G.; Biochemistry 2003, 42, 10288.

32. Fathi, F.; Dolatanbadi, J. E. N.; Rashidi, M.; Omidi, Y.; Int. J. Biol. Macromol. 2016, 91, 1045.

33. Ehteshami, M.; Rasoulzadeh, F.; Mahboob, S.; Rashidi, M.; J. Lumin. 2013, 135, 164.

34. Paul, B. K.; Ghosh, N.; Mukherjee, S.; RSC Adv. 2016, 6, 9984.

35. Liu, L.; Guo, Q.; Chem. Rev. 2001, 101, 673.

Submitted: March 26, 2020

Published online: July 14, 2020 